\title{
Sexualidade no envelhecimento: relatos de idosos
}

\author{
Izabella Lenza Crema, ${ }^{(D)}$ * Rafael De Tilio \\ Universidade Federal do Triângulo Mineiro, Uberaba, MG, Brasil
}

\begin{abstract}
Resumo
A sexualidade envolve aspectos biológicos e subjetivos e está presente ao longo do desenvolvimento humano. O objetivo desta pesquisa foi investigar relatos de idosos sobre sexualidade no envelhecimento. Foram realizadas entrevistas com dez idosos da Universidade Aberta à Terceira Idade de uma cidade da região do Triângulo Mineiro, cujos resultados foram organizados e analisados por meio de uma análise de conteúdo temática. As duas categorias constituídas ressaltam concepções tradicionais de gênero e sexualidade: no geral, são homens idosos autodeclarados viris, sexualmente potentes e com elevada frequência de relações sexuais, e mulheres idosas autodeclaradas sexualmente desinteressadas (após a menopausa) que se submetem aos desejos e satisfações masculinas. Em comum, ambos destacam a importância da convivência e do diálogo para a manutenção de seus relacionamentos afetivo-sexuais de longa duração. Em suma, a intersecção entre gênero e geração (envelhecimento) replica a lógica heteronormativa e a desigualdade entre homens e mulheres idosos.
\end{abstract}

Palavras-chave: envelhecimento; sexualidade; gênero.

\section{Sexuality in aging: reports of the elderly}

\begin{abstract}
Sexuality involves biological and subjective issues and is present in human development. The objective of this research was to investigate the elderly's reports on sexuality in aging. Interviews were conducted with ten elderly whose results were organized and analyzed through a thematic content analysis. The two categories emphasize gender and sexuality traditional conceptions: in general, elderly men self-declared his potent and his high frequency of sexual relations, besides elderly women self-declared her sexual disinterested (after menopause) and her submit to male sexual desires. In common, both highlight the importance of coexistence and dialogue for the maintenance of their long-term relationships. In short, the intersection between gender and generation (aging) replicates heteronormativity logic and an inequality between elderly men and women.
\end{abstract}

Keywords: aging; sexuality; gender.

\section{La sexualidad en el envejecimiento: relatos de ancianos}

\begin{abstract}
Resumen
La sexualidad implica aspectos biológicos y subjetivos y está presente durante todo el desarrollo humano. El objetivo de esta investigación fue compreender los relatos de ancianos sobre la sexualidad en el envejecimiento. Se realizaron entrevistas a diez ancianos de la Universidade Aberta à Terceira Idade de una ciudad de médio porte em Brasil, cuyos resultados se organizaron y analizaron mediante un análisis de contenido temático. Las dos categorías destacaron las concepciones tradicionales de género y sexualidad: en general, se trata de viejos autodeclarados viriles, sexualmente potentes y con alta frecuencia de relaciones sexuales $y$ de viejas autodeclaradas desinteresadas sexualmente (después de la menopausia) que se someten a los deseos y satisfacciones masculinos. En común, ambos destacan la importancia de la convivencia y el diálogo para el mantenimiento de sus relaciones afectivo-sexuales. En resumen, la intersección entre el género y la generación (envejecimiento) reproduce la lógica heteronormativa y la desigualdad entre hombres y mujeres ancianas.
\end{abstract}

Palabras clave: envejecimiento; sexualidad; género.

O Estatuto do Idoso (BRASIL, 2003) considera idosas pessoas com idade superior a 60 anos, e essa população no Brasil tem apresentado crescimento expressivo. Em 2010 pouco mais de $10 \%$ da população era de idosos (INSTITUTO BRASILEIRO DE GEOGRAFIA E ESTATÍSTICA [IBGE], 2011), sendo este o estrato populacional com maior crescimento (FRUGOLI; MAGALHÃES-JÚNIOR, 2011). Ademais, há uma feminização da velhice no Brasil: as mulheres são 55,5\% dentre os maiores de 60 anos e $61 \%$ dentre os maiores de 80 anos (IBGE, 2011).

\footnotetext{
^Endereço para correspondência: Universidade Federal do Triângulo Mineiro, Instituto de Educação, Letras, Artes, Ciências Humanas e Sociais. Rua Vigário Carlos, 100, sala 525. Nossa Senhora da Abadia - Uberaba, MG - Brasil. CEP. 38025350.E-mails: bella lenzacrema@hotmail.com, rafael.tilio@uftm.edu.br Os dados completos dos autores encontram-se ao final do artigo.
}

O envelhecimento é um processo contínuo e permeado por transformações físicas, emocionais, subjetivas e sexuais, sendo que a história pessoal e o contexto sociocultural influenciam os modos do envelhecer. Gênero, classe social, saúde, educação, personalidade, histórico de vida e contexto socioeconômico acarretam diferenças no envelhecimento e entre os idosos. Assim, se a idade cronológica fornece indicativos sobre aspectos corporais ou fisiológicos, ela não determina as experiências individuais dos idosos (SANTOS, 2011).

O paradigma de desenvolvimento ao longo de toda a vida (life-span) do psicólogo alemão Paul Baltes (19392006) é relevante para o estudo do envelhecimento ao enfatizar os ganhos deste processo (longevidade, amadurecimento subjetivo e aquisição de experiências) e questionar a simples associação entre envelhecimen- 
to e declínio (BIASUS; DEMANTOVA; CAMARGO, 2011; ORDONEZ; CACHIONI, 2011). Além disso, nas últimas décadas podem ser observadas melhoras na qualidade de vida na velhice resultantes de diversificadas políticas sociais (SANTANA, 2011), que destacam o envelhecimento como um processo interacional, dinâmico e contextualizado por alterações genético-biológicas e psicossociais, constituindo uma experiência heterogênea e única (NERI, 2006, 2011).

Por sua vez, a sexualidade está presente ao longo de todo o desenvolvimento humano e é composta por elementos biológicos (instintos), subjetivos (sentimentos, desejos) e sociais (relações e interações) (ARAÚJO et al. 2013). Barreto e Heloani (2011) argumentam que a sexualidade não se restringe às relações sexuais (coito), ela envolve atitudes (sentimentos, representações e ações) e interações sociais. Ressalta-se a participação da cultura na constituição e expressão da sexualidade, uma vez que ela se atrela aos papéis socialmente orientados e valorizados (ARAÚJO et al., 2013).

O conceito de gênero pode ser igualmente importante para a compreensão da sexualidade no envelhecimento. Para Butler (2016) os atributos de gênero usualmente atribuídos aos homens e às mulheres não são determinados pelas diferenças biológicas, mas sim em decorrência de uma lógica heterossexual propagada pelos discursos hegemônicos que estabelecem padrões de normalidade. Para a autora, disso resultam pressões em nossa sociedade para uma adequação entre sexo biológico, identidade pessoal e orientação sexual - heteronormatividade compulsória ou tradicionalismo de gênero. Os tradicionalismos de gênero contribuem para o estabelecimento de relações de poder entre homens e mulheres que se refletem em suas vivências, incluindo as sexuais. No geral, esses tradicionalismos requerem homens provedores/detentores de poder atuando na esfera pública e mulheres responsáveis pelas atividades domésticas e cuidados com os familiares na esfera privada - sistemática que inclui os idosos (RODRIGUES, 2013; SILVA, K.; SANTIADO, 2014).

Para Biasus, Demantova e Camargo (2011), Rodrigues (2013), Silva, K. e Santiado (2014), o senso comum espera que o exercício da sexualidade diminua de forma drástica ou cesse no envelhecimento devido à menopausa e à redução da resposta genital. Todavia, pesquisas apontam que o desejo sexual não cessa com o envelhecimento (DEBERT; BRIGEIRO, 2012; ALVES-SILVA; SCORSOLINI-COMIN; SANTOS, 2016). Destarte, tanto o envelhecimento como a sexualidade são fenômenos socialmente constituídos que influenciam os modos como os idosos atribuem significados a essas vivências (VIEIRA; MIRANDA; COUTINHO, 2012).

Neste sentido, no caso dos atuais idosos há de se considerar que provavelmente foram socializados e desenvolveram seus relacionamentos afetivos e sexuais em um contexto histórico marcado por tensões, ambiguidades e contradições: se por um lado o Brasil padeceu de severa repressão (inclusive dos costumes e das práticas sexuais) durante a ditadura militar (décadas de 1960 e 1980) e durante a pandemia de HIV/AIDS (décadas de
1980 e 1990), por outro lado também foi influenciado pelos movimentos feministas e LGBTQ, pautados por questionamentos e resistências aos tradicionalismos e às desigualdades sociais, sexuais e de gênero, visando $\grave{a}$ busca pelo prazer na denominada revolução sexual (década de 1960 e seguintes) (BRANDÃO, 2016; SOUSA et al., 2012). Contudo, mesmo neste cenário de disputas os tradicionalismos de gênero (representados pelo casamento heterossexual e pela rígida divisão de papéis entre os gêneros) permaneceram dominantes, apesar de não mais hegemônicos ${ }^{1}$ (BRANDÃO, 2016), destacando a presença do dispositivo (de controle) da sexualidade nas vivências íntimas (FOUCAULT, 2014).

Assim, retomando o exposto e considerando que na atualidade o processo de envelhecimento passa por mudanças demográficas e, principalmente, simbólicas, ele pode ser significado como um período potencialmente produtivo e prazeroso sexualmente, impulsionando propostas de atendimento, serviços e atividades coerentes com as necessidades e demandas dos idosos (ALVES-SILVA; SCORSOLINI-COMIN; SANTOS, 2016). Uma dessas propostas são as Universidades Abertas à Terceira Idade (UATI), cujos propósitos são a melhora da qualidade de vida, do bem-estar psicológico e social, a promoção da saúde, a aprendizagem contínua e a reconstrução dos significados sobre o envelhecer ${ }^{2}$ (CACHIONI et al, 2021; ORDONEZ; CACHIONI, 2009; PEREIRA et al., 2011). O objetivo desta pesquisa foi investigar relatos de idosos sobre sexualidade no envelhecimento.

\section{Método}

\section{Tipo de estudo}

Trata-se de um estudo exploratório embasado na abordagem qualitativa de pesquisa. Esta pesquisa foi aprovada pelo Comitê de Ética em Pesquisa da universidade dos pesquisadores (CAAE 32290214.8.0000.5154 na Plataforma Brasil), que observou todas as orientações das Resoluções 466/12 e 510/16 do CNS.

\section{Procedimentos de coleta de dados}

A opção de realizar o recrutamento dos participantes naquela UATI se deu porque ela estava sediada na universidade de origem dos pesquisadores e também porque eles possuíam contatos profissionais com os coordenadores da UATI. Após a aprovação da pesquisa pelo Comitê de Ética em Pesquisa, ocorreu uma reunião com a coordenadora-geral da UATI para a apresentação dos objetivos da pesquisa. Em seguida, o responsável pelas atividades realizadas com os idosos foi contatado para auxiliar no primeiro encontro dos pesquisadores com os idosos em uma das aulas da UATI, momento no qual a proposta da pesquisa foi apresentada a todos os idosos (cerca de 80).

\footnotetext{
${ }^{1}$ Esses questionamentos impulsionaram, dentre outros, a crescente inserção e participação das mulheres na escolarização formal e no mercado formal de trabalho, o reconhecimento de outros modelos/dinâmicas de relações afetivas e sexuais além do casamento heterossexual e sua perenidade, os direitos sobre abortos e outros direitos sexuais e reprodutivos, os enfretamentos às violências contra mulheres e LGBTIQA+.

${ }^{2}$ Apesar do nome, as UATIs não atribuem titulações de nível superior (graduações ou pós-graduações). Elas são ações promovidas por instituições de ensino superior visando proporcionar a esta população (independentemente do nível de educação do participante) o livre acesso à universidade para atualização do conhecimento.
} 
Os que demonstraram interesse (dez, apenas) foram convidados para uma entrevista individual, na qual foram apresentados os termos de consentimento livre e esclarecido que informavam os objetivos, justificativas, procedimentos, riscos e benefícios da pesquisa. As entrevistas foram realizadas em salas reservadas do serviço-escola de atendimento psicológico da universidade dos pesquisadores, que possui condições adequadas para o resguardo do sigilo e conforto físico e emocional dos participantes. As entrevistas foram realizadas individualmente entre outubro e dezembro de 2014, audiogravadas após permissão dos participantes e transcritas na íntegra para análise.

\section{Participantes}

Os nomes dos participantes foram substituídos por nomes fictícios a fim de garantir o sigilo de identidade. A amostra foi composta por dez idosos (seis mulheres e quatro homens) que respondiam aos critérios de inclusão (maiores de 60 anos e frequentadores da UATI). Os participantes seriam excluídos em caso de óbito ou desistência durante a pesquisa - o que não ocorreu.

Os participantes e suas principais características são as seguintes: Aparecida, 70 anos, casada há 42 anos, vida sexual ativa, ensino médio completo, aposentada (tarefas domésticas), católica, frequentava a UATI há dois anos e seis meses; Diana, 66 anos, viúva (casamento de 40 anos e, depois, namoro de seis anos), vida sexual inativa, ensino fundamental incompleto, aposentada (trabalhos domésticos e voluntariado), católica, frequentava a UATI há um ano e seis meses; Elaine, 70 anos, casada há 48 anos, vida sexual ativa, ensino médio completo, aposentada (trabalhos domésticos e voluntariado), católica, frequentava a UATI há três anos; Heloisa, 75 anos, viúva (casamento de 32 anos), vida sexual inativa, ensino superior completo, aposentada (trabalhos domésticos e voluntariado), católica, frequentava a UATI há dois anos; Lilian, 64 anos, casada há 34 anos, vida sexual inativa, ensino médio completo, aposentada (trabalhos domésticos, educacionais e voluntariado), espírita, frequentava a UATI há sete meses; Marisa, 76 anos, casada há 53 anos, vida sexual ativa, ensino médio completo, dona de casa, católica, frequentava a UATI há dois anos; Cristiano, 70 anos, casado há 32 anos, vida sexual ativa, ensino médio incompleto, aposentado (mas atua como segurança e voluntariado), católico, frequentava a UATI há três anos; Jorge, 71 anos, casado há 39 anos, vida sexual ativa, ensino superior completo, aposentado, católico, frequentava a UATI há três anos; Josué, 72 anos, casado há 50 anos, vida sexual ativa, ensino médio completo, aposentado (atua em voluntariado), católico, frequentava a UATI há dois anos; Marcos, 76 anos, casado há 42 anos, vida sexual inativa, ensino médio completo, aposentado, espírita, frequentava a UATI há três anos.

\section{Instrumento de coleta dos dados}

Para a coleta dos dados foi utilizado um roteiro de entrevista semiestruturado, elaborado pelos pesquisadores, que abordava os seguintes temas: dados pessoais dos participantes; rotinas; atividades prazerosas; tempo que frequenta a UATI; motivações para o ingresso na UATI; conhecimentos e experiências acerca da sexualidade no envelhecimento; fontes de informação sobre sexualidade; influências da participação na UATI sobre a sexualidade; relacionamentos afetivos e vida sexual.

\section{Procedimentos de análise dos dados}

Os dados foram organizados de acordo com a análise de conteúdo temática, modalidade da análise de conteúdo que enfatiza a noção de tema, ou seja, palavras, frases ou argumentos de mesmo sentido que compõem uma comunicação (TURATO, 2008). Duas categorias foram constituídas a posteriori: Tradicionalismos de gênero (papéis de gênero e padrões de sexualidade considerados tradicionais e socialmente aceitos) e Problematizações sobre envelhecimento e sexualidade (vivências atuais da sexualidade contrapostas à concepção de velhice assexuada ou inativa). Para a análise dos dados foram utilizadas produções científicas sobre sexualidade, gênero e intergeracionalidade.

\section{Resultados e Discussão}

\section{Caracterização dos participantes}

Os participantes frequentavam a UATI (em média) há dois anos. Todos os participantes se autodeclararam heterossexuais, mas apenas um casal foi entrevistado (ambos concederam entrevistas individuais). A média de idade dos participantes é de 71 anos (entre 64 e 76 anos), sendo a faixa etária predominante de 70-76 anos (80\%). Em relação à escolaridade, um participante $(10 \%)$ possuía ensino fundamental incompleto (uma mulher), um ( $10 \%)$ possuía ensino médio incompleto (um homem), seis $(60 \%)$ concluíram o ensino médio (quatro mulheres e dois homens) e dois (20\%) completaram o ensino superior (uma mulher e um homem).

No que se refere à ocupação atual (principais atividades laborais, remuneradas ou não), nove (90\%) disseram ser aposentados (cinco mulheres e quatro homens), entre os quais seis $(60 \%)$ (quatro mulheres e dois homens) continuavam realizando trabalhos voluntários. Somente um dos homens $(10 \%)$ realizava trabalhos temporários com remuneração; os demais não exerciam atividades remuneradas. Apenas uma (10\%) participante não era aposentada, mas todas as mulheres $(60 \%)$ citaram os trabalhos e afazeres domésticos como principal ocupação.

A respeito do estado civil, oito participantes $(80 \%)$ estavam casados e residiam com seus parceiros. Os quatro homens participantes (40\%) estavam casados, e, dentre as mulheres, quatro $(40 \%)$ estavam casadas e duas (20\%) eram viúvas. A média de tempo de casamento/ união estável com o mesmo/atual parceiro foi de 42,5 anos, variando entre 32 e 53 anos. As viúvas relataram que foram casadas durante mais de 30 anos. Em suma, são/foram uniões de longa duração.

Seis participantes (60\%, três homens e três mulheres) relataram que atualmente mantinham relações sexuais, definindo o coito como vida sexual ativa. A frequência de relações sexuais relatada foi a seguinte: duas a três vezes por semana (um homem - 10\%), três vezes por semana (um homem - 10\%), às vezes (sem especificação de tem- 
po; duas mulheres $-20 \%$ ) e uma vez por semana (dois participantes: um homem e uma mulher $-20 \%$ ). Dentre os demais participantes que relataram não manter relações sexuais (coito) na atualidade (quatro, 40\% - um homem e três mulheres), três afirmaram que se masturbavam, e uma disse ser sexualmente abstêmia. A frequência citada de masturbação era duas a três vezes por semana (um homem $-10 \%$ ), às vezes (uma mulher - $10 \%$ ), e uma entrevistada (10\%) não especificou a frequência. Todavia, um fato chama a atenção: nenhum deles considerou a masturbação como vida sexual ou sexualidade ativa.

Relativo ao histórico de parceiros sexuais, todos os homens $(40 \%)$ declararam ter tido mais do que duas parceiras ao longo da vida e ter iniciado a vida sexual com profissionais do sexo ou em relacionamentos casuais antes do casamento. Dentre as idosas, cinco (50\%) informaram que o primeiro parceiro sexual foi o esposo e só após o casamento, e apenas uma (10\%) relatou que o marido foi seu segundo parceiro sexual.

Oito participantes se autodeclararam católicos (80\%) e cinco deles exerciam funções em instituições religiosas. Dois participantes declararam-se espíritas (20\%), sendo que um deles (mulher) realiza trabalhos voluntários em instituições religiosas.

\section{Categoria 1 - Tradicionalismos de gênero}

Os participantes relataram exercer papéis de gênero considerados tradicionais, definindo-os da seguinte maneira: mulheres cuidadoras dos filhos e do marido, responsáveis pela satisfação sexual dos parceiros e pelas atividades domésticas, e homens destinados ao trabalho e sustento da família, com necessidades de relações sexuais frequentes. Isso evidencia concepções distintas e desiguais entre homens e mulheres que são reflexos de relações de poder (sociais e sexuais) historicamente constituídas e influenciadas, inclusive, pela moralidade religiosa dos participantes (BUTLER, 2016) - todos os participantes declararam ter religiões de tradição cristã ou práticas religiosas por ela influenciada, que estão assentadas na rígida distinção entre papéis de gêneros.

No que tange à sexualidade, os participantes revelaram constâncias nos discursos sobre masculinidade e feminidade, independentemente do sexo/gênero do respondente. Por isso, os conteúdos desta categoria serão apresentados como Tipicidades Masculinas e Tipicidades Femininas - isto é, discursos que ilustram os tradicionalismos de/entre/e para cada um dos gêneros. Reitera-se que os participantes viveram suas adolescências e parte da vida adulta em um momento histórico marcado por uma profusão de conflituosos discursos sobre a sexualidade (tradicionalismos e conservadorismos decorrentes do moralismo da ditadura militar e do discurso médico típico da pandemia de HIV/AIDS; resistências e questionamentos decorrentes da revolução sexual, dos femininos, dos grupos minoritários de sexualidade e gênero, e dos avanços científicos como a pílula contraceptiva hormonal) (BRANDÃO, 2016).
No entanto, seus relatos destacaram os padrões tradicionalistas heteronormativos, que, predominantes, ditavam que homens e mulheres deveriam possuir rígidos papéis sociais e sexuais: homens responsáveis pelo trabalho no espaço público, sustento e proteção das famílias; mulheres restritas à esfera privada doméstica, cuidando da família. Sob estes termos, a sexualidade feminina deveria estar atrelada à submissão, à reprodução biológica e à maternidade (BRANDÃO, 2016; MORAES et al., 2011).

Sobre as Tipicidades Masculinas foi possível notar que os participantes, tanto homens quanto mulheres, consideravam as relações sexuais para o gênero masculino como uma necessidade biológica, independentemente da idade, e que influenciava o humor e a qualidade de vida, devendo ser satisfeita para manter o bem-estar e a saúde. Exemplos desse argumento são os trechos:

Para mim, o sexo, hoje, eu sei que há necessidade, porque senão você fica nervoso, isso acaba com os nervos. Então, pra mim, ele é algo vital, é importante, porque é através do sexo que você melhora sua cabeça, o seu físico, a sua maneira de pensar. Eu acho que o sexo é base pra um relacionamento, e eu tenho isso, o sexo, assim, não com promiscuidade (Josué, 72 anos).

Porque a gente tem que fazer porque é obrigação. Principalmente o homem, quando ele tá nos 60, no caso do meu marido, ele não consegue ter ereção e ele quer, por ele podia ter relação todo dia, [...] mas me incomoda demais (Elaine, 70 anos).

Nesta pesquisa os homens idosos, mais do que as idosas, relataram maior satisfação pessoal ao manterem relações sexuais em elevadas frequências e descreveram possuir mais desejo por essas atividades. Rodrigues, Duarte e Lebrão (2009) encontraram resultados semelhantes em pesquisa realizada em São Paulo: a importância conferida às relações sexuais na velhice por homens e mulheres é distinta, sendo mais valorizadas pelos idosos do que pelas idosas. Evidencia-se, portanto, segundo esses autores, que as diferenças entre os gêneros influenciam as atitudes e condutas da sexualidade também na velhice: as idosas participantes, após terem cumprido as obrigações da maternidade e cuidado dos dependentes e/ou dos seus companheiros, tendem a se distanciar e se desinteressar das relações sexuais, ao contrário dos homens idosos. Alguns autores argumentam que são as exigências sociais que fazem com que os homens exerçam "uma prática sexual intensa, associada a uma ideia de qualidade de vida ou, mais amplamente, de saúde" (SILVA et al., 2012, p. 178), o que corrobora os relatos dos participantes.

Debert e Brigeiro (2012) apontam os esforços da gerontologia atual ao enfatizar os benefícios e a importância da sexualidade na velhice, ressaltando que o prazer sexual nesta etapa da vida se enquadra nos critérios de uma vida saudável. Todavia, Santos (2011) pondera que essa proposição é generalista e não considera as particularidades dos idosos - como se todos possuíssem as mesmas potencialidades e oportunidades de realização/ satisfação sexual. 
Outro aspecto presente nas entrevistas foi o tradicionalismo relativo ao binômio sexualidade/conjugalidade: os homens citaram evitar relações sexuais com múltiplas parceiras somente após e durante o casamento, devido ao respeito e fidelidade para com a esposa - ao contrário do que ocorria antes do casamento. E a pornografia foi significada como anormal e desrespeitosa para com as parceiras:

Já tive várias oportunidades [de manter relações sexuais fora do casamento], mas eu resolvi, por enquanto, não. Eu penso assim, eu tenho uma família, com a idade que eu tenho, tenho vontade, mas prefiro manter essa vida junto com a minha patroa, porque eu sei que ela me respeita, então eu a respeito. E, então, um bom relacionamento, com respeito mútuo, isso é muito importante (Marcos, 76 anos).

Eu falo para minhas filhas que elas devem seguir direitinho e com o marido também. Saber fazer a sexualidade. Sexualidade, o corpo da gente, é sagrado. Tem que saber usar o corpo. Não fazer coisas extraconjugais, fazer aquilo que é normal, que é permitido por Deus, que nosso corpo é sagrado [...] devemos seguir os mandamentos da Lei de Deus (Jorge, 71 anos).

$\mathrm{O}$ casamento geralmente é associado à estabilidade, à reprodução biológica e à fidelidade mútua, e, mesmo diante das transformações que tensionaram seus significados e possibilidades, tais preceitos mantiveram-se presentes inclusive nos anos 1970 - contexto histórico no qual os idosos desta pesquisa se casaram. Assim, a constituição familiar padrão (ou idealizada) dos participantes provavelmente se baseava no modelo familiar nuclear, heterossexual, monogâmico e com papéis distintos para homens e mulheres (ZORDAN; FALCKE; WAGNER, 2009).

Desse modo, a contenção da sexualidade após o casamento corresponde às determinações morais típicas da instituição familiar que objetiva controlar e restringir a sexualidade e, mais especificamente, as relações sexuais (FOUCAULT, 2014; SILVA, V. et al., 2012). É importante salientar também que $80 \%$ dos participantes declararam ser católicos e $20 \%$, espíritas, sendo a maioria praticante, e neste sentido tanto os homens como as mulheres relataram seguir os princípios, normas e regras morais dessas religiões/práticas que orientavam suas atitudes sobre a sexualidade. Aguiar, Leal e Marques (2020), em estudo com maioria de idosos católicos, também constataram que estes possuíam atitudes mais conservadoras e tradicionalistas do ponto de vista da moral sexual (pudor, fidelidade, submissão feminina, prazer sexual associado ao pecado etc.).

Esses aspectos podem ser mais bem compreendidos pela recorrência da expressão "normal", utilizada pelos homens idosos entrevistados para caracterizar as relações heterossexuais ocorridas no contexto do casamento estável. Há uma contraposição entre a sexualidade normal e a pornografia e a infidelidade, consideradas por eles desrespeitosas, além de designadas como desnecessárias, pois são dispensáveis aos "homens de verdade". Silva, V. et al. (2012) similarmente ao evidenciado nesta pesquisa, argumentam que há contradições nos discursos sobre a sexualidade masculina: se por um lado há a supervalorização da virilidade e da potência sexual, independentemente da

idade, por outro lado há a influência da moralidade religiosa no casamento, acautelando essa mesma sexualidade de acordo com padrões considerados adequados.

Já em relação às Tipicidades Femininas, a maioria dos participantes destacou as vivências da sexualidade das mulheres atreladas ao sacrifício, desgaste e diminuição - quando não à ausência - de desejo sexual. Nas entrevistas, tanto os homens como as mulheres citaram as relações sexuais como obrigações para muitas delas:

\begin{abstract}
Minha esposa não gosta de sexo. Ela pratica sexo comigo por necessidade, ela não conhece o que é orgasmo. Encontro dificuldade, porque a gente não tem um retorno, de uma maneira geral, mas eu acho que ela também sofre muito mais que eu, porque ela está se expondo a aceitar algo que não está dentro dela, não é uma coisa normal pra ela (Josué, 72 anos).
\end{abstract}

Antigamente era prazerosa. Hoje em dia, não. Hoje é obrigação. E tudo que é feito por obrigação é muito ruim, é muito sofrido. Saber que tem que deitar, tem que fazer. Ai tu imaginas o quanto que uma vida de uma prostituta é triste (Elaine, 70 anos).

Uma das participantes relatou que sofria agressões físicas e verbais quando era casada, e associou as relações sexuais às experiências negativas: "Eu não gosto muito porque parece que ficou uma coisa obrigatória. Quando uma pessoa te bate durante o dia, ai de noite ele fala: você é obrigada, você é casada comigo, você é obrigada a fazer as coisas do jeito que eu quero, e você tem que fazer (Diana, 66 anos).

Parte das idosas participantes apontou a resignação diante da (suposta) necessidade sexual do marido/companheiro em detrimento das próprias vontades: " $\mathrm{Eu}$ vou ser sincera. Eu nunca senti nada. Com o [nome] eu sou casada há mais de 50 anos. Mas eu agrado meu marido. Começou assim e eu acho que vai terminar assim" (Marisa, 76 anos).

Eu me preocupo mais com ele do que comigo. Então, a minha preocupação, a minha cabeça é tentar deixar ele esvaziar, o esvaziamento dele, que, na cabeça dele, ele acha que precisa, né, e não me preocupo comigo, porque pra mim não me faz falta. Porque se eu não fizer muito esforço, não consegue. Só eu sei.... Não desejo pra ninguém que tenha que passar o que eu passo, entendeu? (Elaine, 70 anos).

Dentre as idosas participantes que relataram ter vida sexual ativa, a maioria declarou que agia passivamente visando à satisfação dos companheiros, uma vez que acreditavam ser essa sua função. Araújo et al. (2013) encontraram resultados semelhantes: a maioria das idosas que entrevistaram caracterizaram suas vidas sexuais sem motivação, penosas ou negativas. Os autores evidenciaram nesses discursos a submissão feminina aos valores patriarcais de dominação. Além disso, a violência doméstica sofrida por uma das participantes evidencia uma realidade que impacta o bem-estar, a sexualidade, a segurança e os direitos das mulheres (BRASIL, 2011).

Debert e Brigeiro (2012), em análise de artigos que relacionam gênero e geração, também identificaram, nos discursos das mulheres, a recorrência da obrigatorieda- 
de das relações sexuais com seus parceiros. Para Vieira, Miranda e Coutinho (2012), a repressão sexual vivenciada pelas participantes daquela pesquisa provavelmente reforça a percepção das entrevistadas sobre as relações sexuais, consideradas desnecessárias, desinteressantes e sem sentido para as idosas. Aguiar, Leal e Marques (2020) pontuam que os padrões sexuais opressores, desiguais e repletos de preconceitos limitam a sexualidade feminina e contribuem para o silenciamento das mulheres.

Outra temática destacada no discurso das participantes foi a afirmação dos papéis de cuidado doméstico, materno e marital atribuídos às mulheres:

Ai eu levanto, eu que tomo conta da minha casa, faço café. Quando eu vou para a ginástica eu já deixo tudo organizado para o meu marido. Volto, limpo a casa, faço almoço todos os dias. E, no domingo, o sábado, eu saio, faço a compra da semana todinha andando. Eu tenho, praticamente, uma mesada por semana, meu marido me dá. Ai eu tenho que administrar aquele dinheiro (Elaine, 70 anos).

Diante dos papéis assumidos ao longo da vida, as idosas participantes expuseram que "naturalmente" intensificaram os cuidados, a dedicação à família, o apoio ao marido, filhos e netos, aos familiares doentes e às pessoas mais idosas do que elas que necessitam de cuidados no ambiente familiar, além de exercerem atividades domésticas. Resultados similares foram relatados por Vieira, Miranda e Coutinho (2012), reforçando a expectativa social de cuidado, discrição e distanciamento dos desejos sexuais por parte das idosas.

Além disso, parcela expressiva dos participantes significou a sexualidade como sinônimo exclusivo de relações sexuais, especialmente a penetração vaginal (coito) - similarmente ao relatado por Frugoli e Magalhães-Júnior (2011), Rodrigues, Duarte e Lebrão (2009) e Vieira, Coutinho e Saraiva (2016). Esse argumento consta em alguns trechos das entrevistas: "Eu vejo o sexo como uma questão vital para o relacionamento a dois. E tanto é vital que a gente sabe que a maioria, digamos $80 \%$ dos casamentos, terminam por problemas de sexualidade" (Josué, 72 anos). Ou: "Bom, digamos que é sobre o ato sexual. A gente ouve falar: ah, muitas posições, muitas coisas que na minha idade a gente acha um absurdo" (Diana, 66 anos).

Em contrapartida, três entrevistados (duas mulheres e um homem) apresentaram opiniões divergentes, não limitando a sexualidade ao coito, mas envolvendo desejos (fantasias) e podendo ser vivenciada em diversas etapas da vida:

Além do ato em si, eu acho que ela está no modo de vida, de você conversar, no diálogo, porque, conforme for o seu diálogo com a pessoa, também não te dá nem inspiração para tal, não é? Ele está num olhar, entendeu?, que é o início de tudo. Então, eu acho que o sexo está em quase tudo na vida da gente (Aparecida, 70 anos).

Uma participante declarou ser a masturbação sua única satisfação sexual: "De vez em quando eu me masturbo. Fazer o quê? Não vou ser honesta e sincera com você?

Fractal, Rev. Psicol., v. 33 - n. 3, p. 182-191, 2021
De vez em quando eu me masturbo. É ojeito. Porque descarrega, me dá mais conforto, me equilibra e eu me sinto bem, e não estou fazendo nada errado (Lilian, 64 anos).

Esses últimos trechos das entrevistas dialogam com perspectivas teórico-argumentativas que compreendem a sexualidade como uma experiência não limitada aos aspectos biológicos (genética, necessidades instintivas e reprodutivas) e à penetração. Assim, a sexualidade pode se manifestar de diversas maneiras (atitudes, preferências, fantasias etc.), envolvendo fatores subjetivos (afeto, amor, carinho, contato, ternura, estética e desejo) que não se esgotam com o tempo - em outras palavras: permanecem na velhice (BARRETO; HELOANI, 2011; SANTOS, 2011).

\section{Categoria 2 -Problematizações sobre envelhecimento e sexualidade}

Alguns participantes relataram alterações nas significações da sexualidade ao longo da vida e citaram outras maneiras de vivenciá-la durante o envelhecimento. Mas, ao mesmo tempo em que ocorreu uma modificação de sentidos da sexualidade na velhice (contrapostos às usuais inatividades/assexualidade), muitos dos tradicionalismos continuaram operantes.

Os homens idosos descreveram alterações físicas na sexualidade por causa da velhice, porém afirmaram a continuidade da vida sexual ativa, do desejo e do prazer: "Mas o prazer não deixa de existir. A gente, embora eu, que estou com 71 anos, entendeu, sinto prazer, sinto vontade, entendeu, faço, eu e minha esposa, mantém ato sexual toda semana, entendeu? Então, o ato sexual é muito bom e não termina, de jeito nenhum, com a velhi$c e$ " (Jorge, 71 anos).

De modo similar, pesquisa realizada por Silva, V. et al. (2012) identificou que quase um quarto dos homens idosos declararam ser sexualmente ativos, ainda mais quando possuíam uma companheira fixa. Debert e Brigeiro (2012), em estudos relacionados à sexualidade no envelhecimento, também pontuam que homens idosos reconhecem as mudanças e limitações no desempenho sexual decorrentes do envelhecimento, porém enfatizam as relações sexuais, a virilidade e a libido. Nesta perspectiva, destaca-se a valorização de atributos supostamente típicos do gênero masculino, especialmente a virilidade, a capacidade de manter a ereção/penetração e a atividade sexual ao longo do tempo (ROHDEN; RUSSO, 2011), tal como relatado pelos homens idosos participantes desta pesquisa.

Já grande parte das idosas relatou outros prazeres não restritos às relações sexuais, por exemplo, quando prestam auxílio ao próximo, ao fazerem artesanatos, ao lerem e escreverem, ao cuidar de plantas e animais, nas atividades físicas e na convivência com familiares e amigos: "Gosto de ajudar as pessoas que 'tão' com dificuldade. Gosto de fazer uma visita, de dar uma palavra de apoio. Gosto demais de escrever, de fazer música; tenho muitos CDs que eu mesma fiz" (Marisa, 76 anos).

As participantes consideraram essas formas de obtenção de prazer similares ou mais intensas e significativas do que as relações sexuais. A menopausa foi associada 
à diminuição do desejo sexual, mas não das vivências prazerosas: "Hoje, a sexualidade para mim eu já olho mais como se fosse para as pessoas mais novas. Porque, depois que a gente passa da menopausa, aquilo vai se acomodando, você não tem mais aquela euforia. Aí, eu também passei por essa coisa" (Diana, 66 anos).

Araújo et al. (2013) e Rodrigues (2013) encontraram resultados semelhantes em suas pesquisas ao entrevistar idosas: elas não limitaram a satisfação às relações sexuais e, além disso, diminuíram a importância destas, quando comparadas com outras atividades (atuação religiosa, trabalhos voluntários, atividades físicas, recreações, relacionamentos afetivos e tarefas domésticas). Os autores, assim como encontrado nesta pesquisa, consideram que a educação (formal e não formal) de caráter tradicional e a dupla moral sexual, que diminui a importância da sexualidade feminina, são elementos que fazem com que as idosas busquem satisfações em outras atividades que não as relações sexuais.

Além disso, Biasus, Demantova e Carmargo (2011) refletem sobre a relevância da menopausa como desmotivadora das relações sexuais e das vivências da sexualidade - este argumento foi referido por grande parte das participantes deste estudo. Já as idosas entrevistadas por Crema (2018) destacaram a menopausa como um dos elementos - porém não o único nem o mais significativo - incidentes sobre as transformações nos significados e vivências sexuais durante o envelhecimento. Para Araújo et al. (2013), a relevância da maternidade na socialização das mulheres contribui para considerar que, concluída tal função (reprodução biológica), a vida sexual e as relações sexuais deixam de ser necessárias, o que impulsiona as mulheres a descobrirem novos valores e vivências prazerosas.

Todavia, uma das idosas participantes - tal como Alves-Silva, Scorsolini-Comin e Santos (2016) localizaram em algumas pesquisas - relatou maior interesse pelas relações sexuais após o envelhecimento devido ao aumento da intimidade com o parceiro: "Eu percebi que no começo da vida sexual a gente não tinha assim tanta... aquela sensação de prazer. E com o passar do tempo aguçou mais. Aumentou, claro [...] a gente vai acabando com aquelas vergonhas que a gente tinha" (Heloísa, 75 anos).

A despeito das diferenças entre os gêneros, todos os participantes destacaram a importância do diálogo, do amor, do afeto, da compreensão e do respeito mútuo em suas relações afetivo-sexuais na velhice. Os homens idosos mencionaram que ao longo dos relacionamentos aprenderam a valorizar o respeito, a fidelidade e o carinho, e estes relacionamentos de longa duração foram considerados mais saudáveis do que as relações (afetivas e sexuais) casuais de outrora com profissionais do sexo apenas para satisfazer os desejos sexuais. E as participantes idosas relataram a relevância do diálogo e da cumplicidade para os relacionamentos atuais: "Eu entendo hoje que é uma coisa boa entre os dois, que tem um diálogo muito bonito, que se ama de verdade. E tem um dia gostoso e terminar sua noite legal, nesse modo" (Diana, 66 anos). Ou: "Houve uma mudança, que eu posso dizer de 100\%. Hoje eu pratico o sexo com certa respeitabilidade até a mim mesmo, com a pessoa que eu pratico sexo. E, antigamente, não era assim, era mais levado, né? Era uma coisa, como que diz assim: eu estou pagando (risos). Entende? Pagava como se fosse um objeto" (Cristiano, 70 anos).

Os questionamentos e/ou as mudanças referidas por estes participantes demonstram a complexidade da sexualidade e das relações de gênero que são passíveis de ressignificações ao longo da vida (BUTLER, 2016; LOURO, 2014) e que certamente são influenciadas por complexos fenômenos sociais já citados (BRANDÃO, 2016).

Moraes et al. (2011), em pesquisa sobre a convivência entre casais de idosos no início de relacionamento (ou seja, décadas atrás) e na atualidade, também constataram mudanças nas significações acerca dos relacionamentos afetivos e sexuais: eles relataram maior respeito, amor, união, carinho e companheirismo, o que melhorou suas relações sexuais. Em suma, o fortalecimento dos vínculos afetivos e da intimidade ocorrido durante os relacionamentos foi enfatizado como importante pelos parceiros, isto é, como elementos que precederam e justificaram o aumento de qualidade/satisfação das relações sexuais (SILVA, K.; SANTIADO, 2014).

Contudo, mesmo ocorrendo algumas mudanças de significações a respeito da sexualidade nos relatos dos idosos, algumas crenças, mitos e valores tradicionais permaneceram. Estes estão principalmente relacionados às distinções e diferenciações entre as funções que homens e mulheres devem exercer (ALMEIDA; PATRIOTA, 2009; RODRIGUES, 2013). Os participantes continuaram a referir maior liberdade sexual para os homens (maior número de parceiras, precocidade sexual, necessidade premente de relações sexuais), e, para as mulheres, declararam a importância de possuírem apenas um parceiro sexual durante a vida e iniciarem sua vida sexual somente após o casamento.

Esses aspectos podem ser reiterados, nesta pesquisa, a partir de trechos das entrevistas de algumas idosas, quando teceram críticas ao que consideram ser o padrão dos relacionamentos sexuais dos atuais adolescentes. Elas relataram que a precocidade, liberdade e devassidão sexual (principalmente das mulheres jovens) são comportamentos e valores demasiadamente liberais, transitórios e danosos, compondo uma realidade distinta daquela vivenciada por elas.

Os participantes desta pesquisa ressignificaram na velhice algumas das suas atitudes sobre a sexualidade, porém igualmente reafirmaram alguns valores tradicionais de gênero usualmente atribuídos aos homens e mulheres, independentemente dos seus níveis formais de escolarização. Apesar de a educação ser elemento potencial para a compreensão e a ressignificação das vivências (CACHIONI et al, 2021; LOURO, 2014; PEREIRA et al, 2011; SOUZA et al., 2019) - incluindo as relacionadas à sexualidade e aos gêneros -, esta pesquisa não possui dados suficientes para corroborar esse argumento, ${ }^{3}$ haja vista que,

\footnotetext{
${ }^{3}$ Além disso, o objetivo desta pesquisa não foi o de avaliar as influências da UATI nas vivências/representações sobre sexualidade dos idosos (para isso seriam necessárias outras estratégias de pesquisa), pois a UATI foi apenas o cenário facilitador para o recrutamento da amostra.
} 
diante do diversificado grau/nível de escolarização formal dos participantes, mesmo aqueles com níveis elevados de escolarização reiteraram os elementos/aspectos tradicionais de gênero. Resultado similar foi relatado por Crema e De Tilio (2021) ao entrevistarem idosas que, independentemente dos níveis de escolaridade, relataram que por causa do seu sexo/gênero não tiveram oportunidades de diálogo e discussão sobre sexualidade ao longo da vida.

\section{Considerações finais}

As entrevistas permitem considerar que as principais significações dos participantes sobre sexualidade estão relacionadas aos tradicionalismos de gênero valorizados pelo dispositivo heteronormativo da sexualidade. Os participantes, quase em sua totalidade, possuem/possuíram relacionamentos afetivos e sexuais de longa duração e destacaram que a sexualidade significaria relações sexuais heterossexuais e dupla moral sexual reforçada pela família nuclear. Eles ainda relataram que a sexualidade masculina, mesmo no envelhecimento, é necessária, viril, vigorosa, potente e praticada com elevada frequência; e a sexualidade feminina no envelhecimento, devido à menopausa, beira tanto ao desinteresse pessoal pelas relações sexuais quanto à obrigatoriedade de satisfazerem seus companheiros, além de as mulheres procurarem satisfações em outras vivências.

Em suma, desigualdades de gêneros entre idosos/homens e idosas/mulheres, no que se refere à sexualidade, foram assim definidas: para os idosos ela é necessária e prazerosa; para as idosas ela é negativa e desnecessária. Mas, mesmo diante destas permanências, os participantes relataram algumas ressignificações sobre a sexualidade ocorridas no envelhecimento; por exemplo, a satisfação sexual mútua decorrente do diálogo e respeito construídos ao longo dos relacionamentos de longa duração e novas possibilidades de prazer não limitadas ao coito o que vai de encontro à suposição da assexualidade no envelhecimento.

De maneira geral, ao investigar os relatos de idosos sobre sexualidade, os resultados permitiram inferir algumas permanências e alterações de sentidos, reforçando a necessidade de articular as categorias gênero e geração e outras categorias interseccionais para uma melhor compreensão desses complexos fenômenos e suas consequências para a qualidade de vida desses sujeitos. Contudo, esta pesquisa possui alguns limites, como o fato de a amostra ser composta por idosos de apenas um cenário de pesquisa de conveniência (UATI); de apenas os efetivamente interessados pelo tema terem sido entrevistados; e de todos serem heterossexuais inseridos em relacionamentos de longa duração, e com boas ou razoáveis condições de saúde. Por isso, caso o recrutamento ocorresse de maneira aleatória (sorteio), ou os participantes fossem idosos homossexuais, ou fossem idosos sem relacionamentos afetivos e sexuais, ou em relacionamentos que não os de longa duração, certamente os resultados seriam outros. Neste sentido, outras pesquisas que abordem estas especificidades são necessárias e bem-vindas.
Assim, mesmo que a amostra desta pesquisa não represente a população idosa em geral, ela pode ser representativa de estratos das comunidades idosas que procuram, por diversos motivos, por melhor qualidade de vida durante o envelhecimento. E, a despeito dos diferentes níveis de escolarização formal dos participantes, $o$ fato de participarem da UATI e de suas ações corrobora essa suposição - já que visam à socialização e atualização do conhecimento.

Espera-se, assim, que esta pesquisa possa contribuir para a atenção às demandas, necessidades e desejos de idosos em seus relacionamentos afetivos e sexuais.

\section{Informações sobre os autores:}

\section{Izabella Lenza Crema \\ (iD) https://orcid.org/0000-0001-6929-8579 \\ (3) http://lattes.cnpq.br/9454464780118001}

Psicóloga graduada pela Universidade Federal do Triângulo Mineiro (2015). Mestre em Psicologia pelo Programa de PósGraduação em Psicologia da Universidade Federal do Triângulo Mineiro (2018). Integrante do HUBRIS - Laboratório de Estudos e Pesquisa em Sexualidade e Violência de Gênero. Realiza pesquisas sobre as temáticas: sexualidade, gênero, menopausa, envelhecimento e relacionamentos íntimos. Atua como psicóloga no Centro de Atenção Psicossocial - Álcool e Outras Drogas (CAPS AD - Uberaba/MG), e como psicóloga clínica.

\section{Rafael De Tilio \\ (iD) https://orcid.org/0000-0002-4240-9707 \\ (9) http://lattes.cnpq.br/7770654404514963}

Possui graduação (2002), mestrado (2005) e doutorado (2009) em Ciências (área de Psicologia) pela USP. Realiza pesquisas nas áreas de sexualidades, gêneros e ideologia. É líder do Laboratório de Estudos e Pesquisa em Sexualidade e Gênero (Hubris/UFTM) e Coordenador da Liga de Sexualidade (LiS/UFTM). Membro do Grupo de Trabalho Psicologia e Estudos de Gênero da ANPEPP (Associação Nacional de Pesquisa e Pós-graduação em Psicologia). Docente do Departamento de Psicologia e do Programa de Pósgraduação em Psicologia (PPGP) da UFTM.

\section{Contribuições dos autores:}

Ambos os autores colaboraram ao longo do processo, desde a elaboração até a revisão final do manuscrito. Os autores aprovaram o manuscrito final para publicação.

\section{Como citar este artigo:}

\section{ABNT}

CREMA, Izabella Lenza; DE TILIO, Rafael. Sexualidade no envelhecimento: relatos de idosos. Fractal: Revista de Psicologia, Niterói, v. 33, n. 3, p. 182-191, set./dez. 2021. https://doi. org/10.22409/1984-0292/v33i3/5811

\section{APA}

Crema, I. L., \& De Tilio, R. (2021, Setembro/Dezembro). Sexualidade no envelhecimento: relatos de idosos. Fractal: Revista de Psicologia, 33(3), 182-191. doi: https://doi.org/10.22409/19840292/v33i3/5811

\section{Copyright:}

Copyright (C) 2021 Crema, I. L., \& De Tilio, R. Este é um artigo em acesso aberto distribuído nos termos da Licença Creative Commons Atribuição que permite o uso irrestrito, a distribuição e reprodução em qualquer meio desde que o artigo original seja devidamente citado. 
Copyright (C) 2021 Crema, I. L., \& De Tilio, R. This is an Open Access article distributed under the terms of the Creative Commons Attribution License, which permits unrestricted use, distribution, and reproduction in any medium, provided the original article is properly cited.

\section{Referências}

AGUIAR, Rosaline Bezerra; LEAL, Márcia Carréra Campos; MARQUES, Ana Paula de Oliveira. Conhecimento e atitudes sobre sexualidade em pessoas idosas com HIV. Ciência \& Saúde Coletiva [online], v. 25, n. 6, p. 2051-2062, 2020. https:// doi.org/10.1590/1413-81232020256.18432018

ALMEIDA, Lucimêre Alves; PATRIOTA, Lúcia Maria. Sexualidade na terceira idade: um estudo com idosas usuárias do Programa Saúde da Família do bairro das cidades - Campina Grande/PB. Qualitas Revista Eletrônica, v. 8, n. 1, p. 1-20, 2009. Disponível em: http://arquivo.revista.uepb.edu.br/index. php/qualitas/article/view/397/274. Acesso em: 18 out. 2019.

ALVES-SILVA, Júnia Denise; SCORSOLINI-COMIN, Fábio; SANTOS, Manoel Antônio dos. Conjugalidade e casamentos de longa duração na literatura científica. Contextos Clínicos [online], v. 9, n. 1, p. 32-50, 2016. http://dx.doi.org/10.4013/ ctc. 2016.91 .03

ARAÚJO, Ivonete Alves de et al. Representações sociais da vida sexual de mulheres no climatério atendidas em serviços públicos de saúde. Texto \& Contexto - Enfermagem [online], v. 22 , n. 1, p. 114-122, 2013. https://doi.org/10.1590/S010407072013000100014

BARRETO, Margarida; HELOANI, Roberto. Sexualidade e envelhecimento. In: TRENCH, Belkis; ROSA, Tereza Etsuko Costa (Org.). Nós e o outro: envelhecimento, reflexões, práticas e pesquisa. São Paulo: Instituto de Saúde, 2011. p. 77-95.

BIASUS, Felipe; DEMANTOVA, Aline; CAMARGO, Brigido Vizeu. Representações sociais do envelhecimento e da sexualidade para pessoas com mais de 50 anos. Temas em Psicologia, Ribeirão Preto v. 19, n. 1, p. 319-336, 2011. Disponível em: http://pepsic.bvsalud.org/scielo. php?script=sci_arttext\&pid=S1413-389X2011000100025\&lng $=$ pt\&nrm=iso. Acesso em: 19 out. 2019.

BRANDÃO, Renata Rodrigues. Revolução sexual e sexualidades "ex-cêntricas": análises das práticas discursivas sobre "identidades sexuais" em revistas brasileiras (19691979). Esboços: histórias em contextos globais, Florianópilis, v. 23 , n. 35 , p. 118-144, 2016. https://doi.org/10.5007/21757976.2016v23n35p117

BRASIL. Presidência da República. Casa Civil. Subchefia para Assuntos Jurídicos. Lei $n^{\circ} 10.741$, de $1^{\circ}$ de outubro de 2003. Dispõe sobre o Estatuto do Idoso e dá outras providências. 2003. Disponível em: http://www.planalto.gov.br/ccivil_03/ leis/2003/L10.741.htm. Acesso em: 12 ago. 2018.

BRASIL. Presidência da República. Secretaria de Políticas para as Mulheres. Política Nacional de Enfrentamento à Violência Contra as Mulheres. Brasília: Ideal, 2011.

BUTLER, Judith. Problemas de gênero: feminismo e subversão da identidade. Rio de Janeiro: Civilização Brasileira, 2016.

CACHIONI, Meire et al. Fatores preditores de bem-estar em idosos participantes de uma UATI. Psicologia: Teoria e Pesquisa [online], v. 37, e37102, 2021. https://doi. org/10.1590/0102.3772e37102
CREMA, Izabella Lenza. Sexualidade, gênero e geração: significados e experiências de idosas na pós-menopausa. 2018. 113f. Dissertação (Mestrado em Psicologia) - Universidade Federal do Triângulo Mineiro, Uberaba, Minas Gerais, 2018.

CREMA, Izabella Lenza; DE TILIO, Rafael. Gênero e sexualidade nos relacionamentos íntimos: significados e experiências de idosas. Psicologia: Teoria e Prática, São Paulo, v. 23, n. 2, p. 1-22, 2021. http://dx.doi.org/10.5935/1980-6906/ ePTPSP12948

DEBERT, Guita; BRIGEIRO, Mauro. Fronteiras de gênero e a sexualidade na velhice. Revista Brasileira de Ciências Sociais [online], v. 27, n. 80, p. 37-54, 2012. https://doi.org/10.1590/ S0102-69092012000300003

FOUCAULT, Michel. História da sexualidade: a vontade de saber. Rio de Janeiro: Paz e Terra, 2014. v. 1.

FRUGOLI, Angélica; MAGALHÃES-JÚNIOR, Carlos Alberto de Oliveira. A sexualidade na terceira idade na percepção de um grupo de idosas e indicações para a educação sexual. Arquivos de Ciências da Saúde da UNIPAR, v. 15, n. 1, p. 85-93, 2011. Disponível em: https://revistas.unipar.br/index.php/saude/ article/view/3696. Acesso em: 21 abr. 2019.

INSTITUTO BRASILEIRO DE GEOGRAFIA E ESTATÍSTICA. Sinopse do Censo Demográfico de 2010. Rio de Janeiro: IBGE, 2011. Disponível em: http://biblioteca.ibge. gov.br/visualizacao/livros/liv49230.pdf. Acesso em: 12 jun. 2020

LOURO, Guacira Lopes. Gênero, sexualidade e educação: uma perspectiva pós-estruturalista. Petrópolis: Vozes, 2014.

MORAES, Késia Marques et al. Companheirismo e sexualidade de casais na melhor idade: cuidando do casal idoso. Revista Brasileira de Geriatria e Gerontologia, Rio de Janeiro, v. 14, n. 4, p. 787-798, 2011. Disponível em: https://www.redalyc.org/ articulo.oa?id=403834044018. Acesso em: 12 abr. 2018.

NERI, Anita Liberalesso. O legado de Paul B. Baltes à Psicologia do Desenvolvimento e do Envelhecimento. Temas em Psicologia, Ribeirão Preto, v. 14, n. 1, p. 1734, 2006. Disponível em: http://pepsic.bvsalud.org/scielo. php? script=sci arttext\&pid=S1413-389X2006000100005. Acesso em: 17 nov. 2018.

NERI, Anita Liberalesso. Teorias psicológicas de envelhecimento: percurso histórico e teorias atuais. In: FREITAS, Elizabeth Viana de; PY, Ligia (Org.). Tratado de Geriatria e Gerontologia. Rio de Janeiro: Guanabara Koogan, 2011. p. 34-46.

ORDONEZ, Tiago Nascimento; CACHIONI, Meire. Universidade aberta à terceira idade: a experiência da Escola de Artes, Ciências e Humanidades. Revista Brasileira de Ciências do Envelhecimento Humano [online], v. 6, n. 1, p. 74-86, 2009. Disponível em: http://seer.upf.br/index.php/rbceh/article/ view/150. Acesso em: 22 maio 2019.

ORDONEZ, Tiago Nascimento; CACHIONI, Meire. Motivos para frequentar um programa de educação permanente: relato dos alunos da universidade aberta à terceira idade da Escola de Artes, Ciências e Humanidades da Universidade de São Paulo. Revista Brasileira de Geriatria e Gerontologia [online], v. 14, n. 3, p. 461-474, 2011. https://doi.org/10.1590/S180998232011000300007 
PEREIRA, Ana Alice da Silva et al. A experiência da psicologia na UATI: formação acadêmica e benefícios. In: CONGRESSO NACIONAL DE PSICOLOGIA ESCOLAR E EDUCACIONAL, 10, 2011, Maringá. Anais ... Maringá: UEM, 2011. p. 6-13. Disponível em: https://www.yumpu.com/pt/ document/read/34303317/a-experiancia-da-psicologia-na-uatiformaaao-. Acesso em: 17 nov. 2019.

RODRIGUES, Carlos Lima. Sexualidade e envelhecimento: uma análise da relação atividade e satisfação sexual. 2013. Tese (Doutorado em Epidemiologia) - Faculdade de Saúde Pública, Universidade de São Paulo, São Paulo, 2013. https:// doi.org/10.11606/T.6.2013.tde-14082014-092412

RODRIGUES, Carlos Lima; DUARTE, Yeda Aparecida de Oliveira; LEBRÃO, Maria Lúcia. Gênero, sexualidade e envelhecimento. Saúde Coletiva, São Paulo, v. 6, n. 30, p. 109-112, 2009. Disponível em: https://www.redalyc.org/ pdf/842/84212132004.pdf. Acesso em: 30 dez. 2019.

ROHDEN, Fabíola; RUSSO, Jane. Diferenças de gênero no campo da sexologia: novos contextos e velhas definições. Revista Saúde Pública [online], v. 45, n. 4, p. 722-729, 2011. https://doi.org/10.1590/S0034-89102011005000038

SANTANA, Maria da Silva. Dimensão psicossocial da atividade física na velhice. Fractal: Revista de Psicologia, Niterói, v. 23, n. 2, p. 337-352, 2011. https://doi.org/10.1590/ S1984-02922011000200008

SANTOS, Sueli Souza dos. Sexualidade e velhice. In: FREITAS, Elizabeth Viana de; PY, Ligia (Org.). Tratado de Geriatria e Gerontologia. Rio de Janeiro: Guanabara Koogan, 2011. p. 1543-1546.

SILVA, Karolyne Germana; SANTIADO, Idalina Freitas. Um estudo sobre as relações de gênero e sexualidade no processo de feminização e envelhecimento da epidemia do HIV/AIDS. Qualitas Revista Eletrônica [online], v. 15, n. 2, p. 1-21, 2014. Disponível em: http://arquivo.revista.uepb.edu.br/index.php/ qualitas/article/view/2221. Acesso em: 29 dez. 2019.

SILVA, Viviane Xavier de Lima et al. Satisfação sexual entre homens idosos usuários da atenção primária. Saúde e Sociedade [online], v. 21, n. 1, p. 171-180, 2012. https://doi.org/10.1590/ S0104-12902012000100017

SOUSA, Adelaine Maria de et al. A política da AIDS no Brasil: uma revisão da literatura. Journal of Management \& Primary Health Care [online], v. 3, n. 1, p. 62-66, 2012. https://doi. org/10.14295/jmphc.v3i1.119

SOUZA, Cinoélia Leal de et al. Envelhecimento, sexualidade e cuidados de enfermagem: o olhar da mulher idosa. Revista Brasileira de Enfermagem [online], v. 72, suppl. 2, p. 71-78, 2019. https://doi.org/10.1590/0034-7167-2018-0015

TURATO, Egberto Ribeiro. Tratado da metodologia da pesquisa clínico-qualitativa: construção teórico-epistemológica, discussão comparada e aplicação nas áreas da saúde e humanas. Petrópolis, RJ: Vozes, 2008.

VIEIRA, Kay Francis Leal; COUTINHO, Maria da Penha de Lima; SARAIVA, Evelyn Rúbia de Albuquerque. A sexualidade na velhice: representações sociais de idosos frequentadores de um grupo de conveniência. Psicologia: Ciência e Profissão [online], v. 36, n. 1, p. 196-209, 2016. https://doi.org/10.1590/1982-3703002392013
VIEIRA, Kay Francis Leal; MIRANDA, Rosane de Sousa; COUTINHO, Maria da Penha de Lima. Sexualidade na velhice: um estudo de representações sociais. Psicologia e saber social [online], v. 1, n. 1, p. 120-128, 2012. https://doi.org/10.12957/ psi.saber.soc. 2012.3250

ZORDAN, Eliana Piccoli; FALCKE, Denise; WAGNER, Adriana. Casar ou não casar?: Motivos e expectativas com relação ao casamento. Psicologia em Revista (Belo Horizonte), v. 15, n. 2, p. 56-76, 2009. Disponível em: http://pepsic. bvsalud.org/scielo.php?script=sci_arttext\&pid=S1677$11682009000200005 \& \operatorname{lng}=p t \& n r m=i$ iso. Acesso em: 14 maio 2018 